\title{
Malnutrition in hospitalised older adults: A multi-centre observational study of prevalence, associations and outcomes
}

\author{
Emma O’ Shea ${ }^{1}$, Steven Trawley ${ }^{2}$, Edmund Manning ${ }^{1}$, Aoife Barrett ${ }^{1}$, Vanessa Browne ${ }^{1}$ and \\ Suzanne Timmons \\ ${ }^{1}$ Centre for Gerontology and Rehabilitation, School of Medicine, University College Cork, Cork, Ireland and \\ ${ }^{2}$ Centre for Health and Social Research, Australian Catholic University, Melbourne, Australia
}

Malnutrition is common in older adults, and is associated with high healthcare costs and adverse outcomes, particularly in hospital settings ${ }^{(1,2)}$. The prevalence and correlates of malnutrition in hospitalised older adults are currently not clear; much of the existing research in this area is limited methodologically; studies are typically based on small samples and/or narrow populations ${ }^{(3,4)}$, exclude people with dementia ${ }^{(3,4)}$, are uni-centre ${ }^{(5)}$, and/or use tools not designed for use with older adults ${ }^{(5)}$. The present study addresses this gap, investigating the prevalence, correlates and outcomes of malnutrition in older adults on admission to hospital.

In total, 606 (70+ years) older adults were included in a prospective cohort study across six hospitals in the Republic of Ireland. All elective and acute admissions to any speciality were eligible. Day-case admissions and those moribund on admission were excluded. All participants were clinically assessed for dementia on admission (see Timmons et al. ${ }^{(6)}$ ). Socio-demographic and clinical data, including nutritional status (Mini-Nutritional Assessment - short form ${ }^{(7)}$, was collected within 36 hours of admission. Outcome data was collected prospectively on length of stay, in-hospital mortality and institutionalisation.

The mean age was 79.7; $51 \%$ were female; $29 \%$ were elective admissions; $67 \%$ were admitted to a medical specialty. Nutrition scores were available for 602/606; $37 \%$ had a 'normal' status, $45 \%$ were 'at-risk', and 18\% were 'malnourished'. Malnutrition was more common in females, acute admissions, older patients and those who were widowed/ separated. Dementia, functional dependency, comorbidity and frailty independently predicted a) malnutrition and b) being at-risk of malnutrition $(p<\cdot 001)$. Malnutrition was also associated with an increased length of stay $(p<.001)$, institutionalisation $(p<0 \cdot 001)$ and in-hospital mortality $(p<.001)$.

These findings support the prioritisation of nutritional screening in clinical practice and public health policy, for all $\geq 70$ on admission to hospital, and in particular for people with dementia, increased functional dependency and/or multi-morbidity, and those who are frail.

1. Rice N, Normand C (2012) The cost associated with disease-related malnutrition in Ireland. Public Health Nutr 15(10): 1966.

2. Rasheed S, Woods RT (2013) Malnutrition and associated clinical outcomes in hospitalized patients aged 60 and older: An observational study in rural Wales. J Nutr Gerontol Geriatr 32(1): 71-80.

3. Chen CC, Bai YY, Huang GH et al. (2007) Revisiting the concept of malnutrition in older people. J Clin Nurs 16(11): 2015-26.

4. Vanderwee K, Clays E, Bocquaert I et al. (2011) Malnutrition and nutritional care practices in hospital wards for older people. J Adv Nurs 67(4): 736-46.

5. Eide HD, Halvorsen K, Almendingen K (2015) Barriers to nutritional care for the undernourished hospitalised elderly: Perspectives of nurses. J Clin Nurs 24(5-6): 696-706.

6. Timmons S, Manning E, Barrett A et al. (2015) Dementia in older people admitted to hospital: A regional multi-hospital observational study of prevalence, associations and case recognition. Age Ageing 44(6): 993.

7. Kaiser M, Bauer JM, Ramsch C et al. (2009) Validation of the mini nutritional assessment short-form (MNA ${ }^{\circledR}-\mathrm{SF}$ ): A practical tool for identification of nutritional status. J Nutr Health Aging 13(9): 782-8. 